\title{
Intradural view of the spinal cord and dura after three-column osteotomy: illustrative case
}

\author{
Zirun Zhao, BS, ${ }^{1}$ Saman Shabani, MD, ${ }^{2}$ Nitin Agarwal, MD, ${ }^{2}$ Praveen V. Mummaneni, MD, MBA, ${ }^{2}$ and Dean $C h o u, \mathrm{MD}^{2}$ \\ ${ }^{1}$ Renaissance School of Medicine, Stony Brook University, Stony Brook, New York; and ${ }^{2}$ Department of Neurological Surgery, University of California, San Francisco, San \\ Francisco, California
}

\begin{abstract}
BACKGROUND A three-column osteotomy results in dural buckling, which may appear concerning upon intraoperative visualization because it may appear that the neural elements may also be buckled. The authors presented an intraoperative view after intentional durotomy of the neural elements and the relaxed state of the dura after three-column osteotomy.

OBSERVATIONS A 52-year-old woman with adult tethered cord syndrome and previous untethering presented with worsening leg pain and stiffness, urinary incontinence, and unbalanced gait. Magnetic resonance imaging demonstrated an arachnoid web at T6 and spinal cord tethering. Spinal column shortening via three-column osteotomy was performed with concomitant intradural excision of the arachnoid web. Dural buckling was observed intraoperatively after spinal column shortening. After the durotomy, the spinal cord was visualized without kinking or buckling.
\end{abstract}

LESSONS Dural buckling after spinal column shortening of $15 \mathrm{~mm}$ via three-column osteotomy at T6 did not result in concomitant buckling of the underlying neural elements.

https://thejns.org/doi/abs/10.3171/CASE21497

KEYWORDS tethered cord syndrome; spinal column shortening; dural buckling

Tethered cord syndrome (TCS) refers to a constellation of signs and symptoms of motor and sensory dysfunction in the lower extremities and bowel and bladder dysfunction. ${ }^{1-4}$ The pathology is believed to result from increased tension on the spinal cord due to caudal traction. ${ }^{5}$ Common etiologies include thickened filum terminale, spinal cord lipoma, lipomyelomeningocele, scoliosis, and injury. ${ }^{5}$ The current gold standard to treat TCS is untethering surgery in both children and adults. ${ }^{6}$ Although it has reported success, especially in pain relief, an untethering procedure carries risks of cerebrospinal fluid (CSF) leaks and wound infection in up to $15 \%$ of patients. ${ }^{1,7,8}$ Furthermore, complete untethering may not always be feasible; symptomatic retethering has been reported in up to $50 \%$ of patients. ${ }^{9}$

Spinal column shortening represents an alternative approach to manage TCS, especially in cases of retethering. First reported by Kokubun et al. in 1995, spinal column shortening has been demonstrated to be a safe and effective treatment for TCS. ${ }^{9-14}$ This approach indirectly relieves the longitudinal tension of tethered neural elements.
However, the dural buckling that can ensue after spinal column shortening can appear concerning intraoperatively, and it is unclear if the underlying neural elements are also kinked. Hitherto, previous reports have not shown an intradural view of the spinal cord after shortening. ${ }^{9,11,13,15}$ Because of the need to concomitantly excise an arachnoid web in this case, the dura was opened. An intraoperative view of the spinal cord and open dura is presented.

\section{Illustrative Case}

Patient History

A 52-year-old woman with a history of adult TCS presented with worsening leg pain and stiffness, urinary incontinence, and gait disturbance. She had initially developed these symptoms 11 years ago and at that time received L5-S1 tethered cord release, which improved her right leg spasms. However, her vesicorectal dysfunction persisted, and muscle spasms recurred over the past year. The patient could only walk a half mile before her legs stiffened. Magnetic resonance imaging

ABBREVIATIONS CSF = cerebrospinal fluid; CT = computed tomography; MRI = magnetic resonance imaging; TCS = tethered cord syndrome . INCLUDE WHEN CITING Published November 8, 2021; DOI: 10.3171/CASE21497.

SUBMITTED September 2, 2021. ACCEPTED October 1, 2021.

(C) 2021 The authors, CC BY-NC-ND 4.0 (http://creativecommons.org/licenses/by-nc-nd/4.0/). 
(MRI) of the thoracic spine demonstrated focal ventral displacement of the spinal cord and a possibly compressive arachnoid web causing cord signal abnormality at T6. A lumbar spine MRI showed the previous detethering site at L5-S1, and the conus medullaris was at L1-L2. Computed tomography (CT) myelogram demonstrated homogenous contrast density without myelographic block at the level of T6, suggesting an arachnoid web (Fig. 1). Because of progressive decline in neurological status, the patient elected to receive spinal column shortening and resection of arachnoid web at the same surgical setting to treat both pathologies.

\section{Operative Description}

After general anesthesia and prone positioning, the posterior thoracic spine was exposed in the usual standard fashion. Pedicle screws were placed into the pedicles of $\mathrm{T} 4, \mathrm{~T} 5, \mathrm{~T} 7$, and $\mathrm{T} 8$, and laminectomies at $\mathrm{T5}$ to $\mathrm{T7}$ were performed. Subsequently, a threecolumn osteotomy of T6 was performed by removing the pedicles, the cancellous bone, the lateral cortical walls, and the posterior cortical wall. A temporary rod was placed at this point to prevent collapse. The ventral vertebral body wall was thinned with a highspeed bur but not excised. The posterior longitudinal ligament was removed, and the spinal column was gently compressed to shorten it by approximately $1.5 \mathrm{~cm}$ (Fig. 2). Permanent rods and set screws were then placed and secured.

At that point, the intraoperative microscope was brought in. We could see dural buckling, and the dura was subsequently opened via a midline incision (Fig. 3). Motor evoked potentials were stable during the entire operation. The arachnoid web was identified, dissected, and excised. The intraoperative view of the spinal cord demonstrated no buckling or kinking of the spinal cord itself despite the dural buckling. The dura was then closed with a 6-0 Prolene (Ethicon) suture and fibrin glue, and the wound was closed in layers after arthrodesis.

\section{Discussion}

\section{Observations}

Revision TCS surgery can be morbid at the index site of tethering because dissecting the spinal cord off the dura can be morbid, risking iatrogenic neurological worsening. ${ }^{16,17}$ Revision untethering also carries risks of CSF leak, pseudomeningocele, infection, and wound complications. ${ }^{6,18}$ In light of these issues, spinal column shortening is an alternative because there is no direct revision detethering, thus decreasing the likelihood of neurological injury. In addition, it mitigates the risk of CSF leak and wound complications by
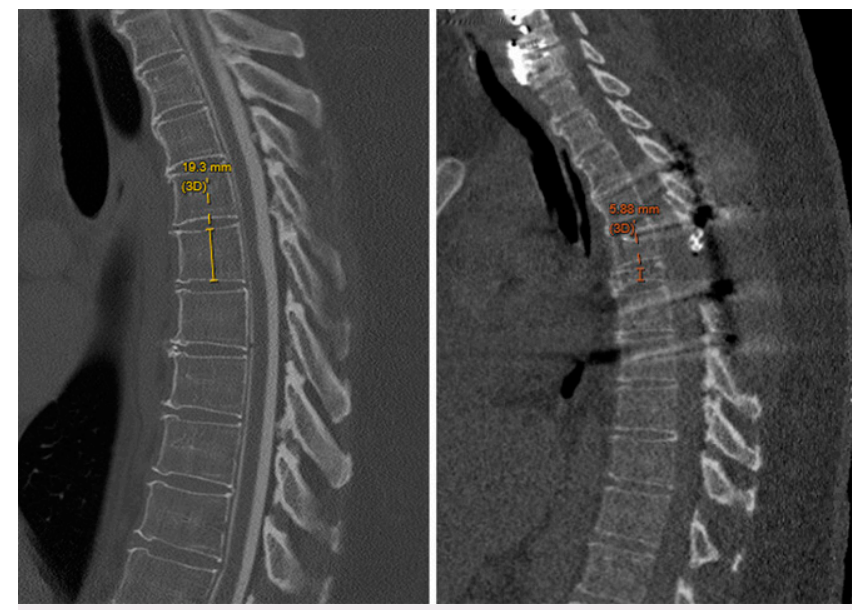

FIG. 2. Preoperative (left) and postoperative (right) lateral radiograph demonstrating reduction of T6 vertebral column from $19.3 \mathrm{~mm}$ to 5.9 $\mathrm{mm}$.

avoiding a previously opened dura and often abnormal, scarred posterior soft tissue.

The rationale for spinal column shortening originates from the cadaveric study by Grande et al., which demonstrated that a shortening of the spinal column by 20 to $25 \mathrm{~mm}$ at the thoracolumbar junction resulted in significant reduction tension of the spinal cord, the lumbosacral nerve roots, and the filum terminale..$^{19}$ In a recent cadaveric experiment by Safain et al., vertebral column resection demonstrated $87.2 \%$ of maximal reduction in spinal cord tension from baseline with $10 \mathrm{~mm}$ of closure. ${ }^{20}$ The authors demonstrated an optimal vertebral column resection of 12 to $16 \mathrm{~mm}$ to maximize tension reduction while minimizing dural buckling. This closure magnitude is lower than that previously reported by Grande et al. and is more like our operative experience. In our present case, a shortening of $15 \mathrm{~mm}$ achieved desirable tension reduction of the spinal cord, evidenced by dural buckling.

Spinal column shortening has been reported to have favorable outcomes for recurrent TCS. Hsieh et al. reviewed 18 cases of spinal column shortening and showed that $86 \%$ of patients recovered complete motor function, $75 \%$ were relieved of debilitating back or lower-extremity pain, and $28 \%$ exhibited improved urological symptoms. ${ }^{9}$ Several other small case series had similar findings and concluded that spinal column
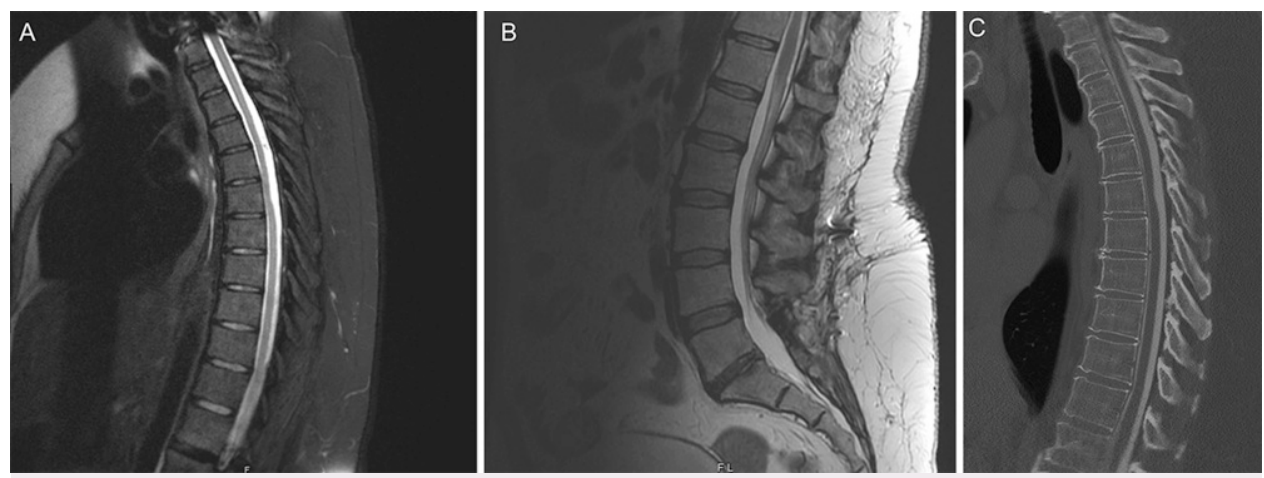

FIG. 1. Preoperative thoracic spine MRI (A), lumbar spine MRI (B), and CT myelogram (C) demonstrating arachnoid web at T6. 


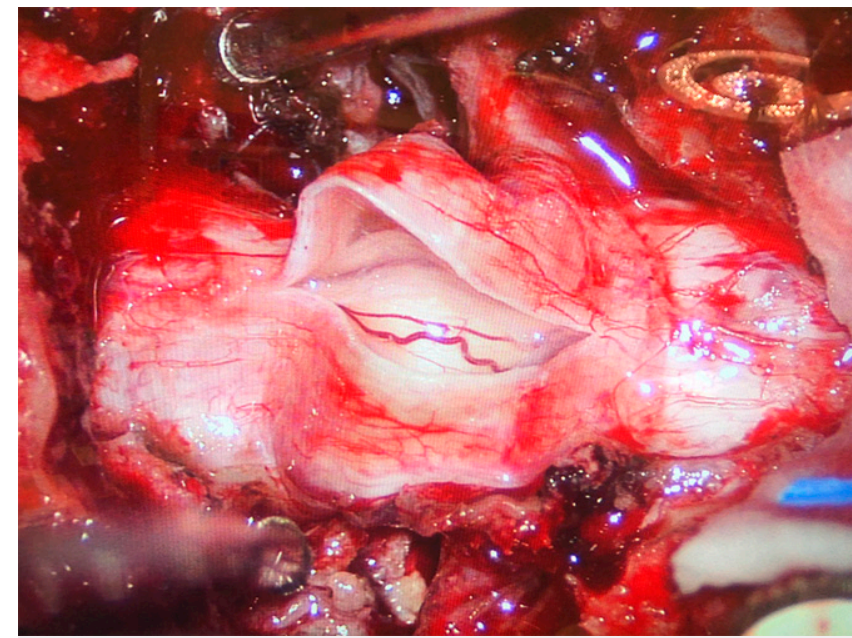

FIG. 3. Intradural view of the spinal cord and dural buckling after spinal column shortening.

shortening is a safe and efficacious treatment option for recurrent TCS in both children and adults. ${ }^{11,13,15} \mathrm{~A}$ meta-analysis conducted by Lin et al. identified six studies with a total of 57 patients. ${ }^{21}$ They found that spinal column shortening resulted in significant improvement in neurological deficit, motor function, sensory symptoms, and bowel and bladder function. McVeigh et al. reported 41 patients undergoing spinal column shortening and demonstrated improved bowel and bladder function, pain and sensory scores, and motor function. ${ }^{12}$ Zhang et al. and Safaee et al. also reported similar findings in patients who received previous detethering procedures. ${ }^{22,23}$

One consideration in this case is that a spinal column shortening may be considered an aggressive procedure over an arachnoid cyst resection or revision detethering. We had discussed the options of cyst excision, revision detethering, and spinal column shortening with our patient, and her case was reviewed at multidisciplinary spine conference. At conference, the cyst itself was not felt to be causing severe cord compression, and the patient had been seen by neurologists, who felt that her symptoms localized to her spinal cord. The totality of the clinical picture was presented to the patient, and because she lived in another state, she wished to receive the most aggressive procedure to give her the best chance of halting neurological progression. Thus, the patient chose to have cyst excision, spinal column shortening, and fusion over the kyphotic apex.

Our current case is unique because the patient concurrently had an arachnoid web at the osteotomy level, affording the rare indication to intentionally open the dura and directly visualize the spinal cord after spinal column shortening. Previous anatomical studies have shown that the optimal decrease in tension in the filum and neural elements is within the range of a 12- to $16-\mathrm{mm}$ vertebral column resection. ${ }^{19,20}$ In our case, we achieved an approximate 15-mm reduction in length, and dural buckling was noted. Intradural visualization of the cord and neural elements after the osteotomy and shortening revealed that although dural buckling was present, there did not appear to be buckling or kinking of the underlying neural elements themselves.

\section{Lessons}

Our case provides a rare opportunity to visualize the spinal cord after spinal column shortening via three-column osteotomy. This report illustrates that although the dura may be significantly buckled, the underlying neural elements are neither buckled nor kinked after a three-column osteotomy and a 15-mm spinal column shortening at T6.

\section{References}

1. Lee GY, Paradiso G, Tator CH, Gentili F, Massicotte EM, Fehlings MG. Surgical management of tethered cord syndrome in adults: indications, techniques, and long-term outcomes in 60 patients. $J$ Neurosurg Spine. 2006;4(2):123-131.

2. Lapsiwala SB, Iskandar BJ. The tethered cord syndrome in adults with spina bifida occulta. Neurol Res. 2004;26(7):735-740.

3. Pang D, Wilberger JE Jr. Tethered cord syndrome in adults. J Neurosurg. 1982:57(1):32-47.

4. Phuong LK, Schoeberl KA, Raffel C. Natural history of tethered cord in patients with meningomyelocele. Neurosurgery. 2002;50(5):989-995

5. Steinbok P, MacNeily AE. Section of the terminal filum for occult tethered cord syndrome: toward a scientific answer. Neurosurg Focus. 2007;23(2):E5.

6. Lew SM, Kothbauer KF. Tethered cord syndrome: an updated review. Pediatr Neurosurg. 2007;43(3):236-248.

7. Mehta VA, Bettegowda C, Ahmadi SA, et al. Spinal cord tethering following myelomeningocele repair. J Neurosurg Pediatr. 2010;6(5):498-505.

8. Thuy M, Chaseling R, Fowler A. Spinal cord detethering procedures in children: a 5 year retrospective cohort study of the early post-operative course. J Clin Neurosci. 2015;22(5):838-842.

9. Hsieh PC, Stapleton CJ, Moldavskiy P, et al. Posterior vertebral column subtraction osteotomy for the treatment of tethered cord syndrome: review of the literature and clinical outcomes of all cases reported to date. Neurosurg Focus. 2010;29(1):E6.

10. Kokubun S. Shortening spinal osteotomy for tethered cord syndrome in adults. Spine Spinal Cord. 1995;8(12 suppl):5.

11. Aldave G, Hansen D, Hwang SW, Moreno A, Briceño V, Jea A. Spinal column shortening for tethered cord syndrome associated with myelomeningocele, lumbosacral lipoma, and lipomyelomeningocele in children and young adults. J Neurosurg Pediatr. 2017;19(6):703-710.

12. McVeigh LG, Anokwute MC, Belal A, et al. Spinal column shortening for secondary tethered cord syndrome: radiographic, clinical, patientreported, and urodynamic short-term outcomes. J Neurosurg Pediatr. Published online May 7, 2021. doi: 10.3171/2020.11.PEDS20847.

13. Nakashima $\mathrm{H}$, Imagama $\mathrm{S}$, Matsui $\mathrm{H}$, et al. Comparative study of untethering and spine-shortening surgery for tethered cord syndrome in adults. Global Spine J. 2016;6(6):535-541.

14. Hsieh PC, Ondra SL, Grande AW, et al. Posterior vertebral column subtraction osteotomy: a novel surgical approach for the treatment of multiple recurrences of tethered cord syndrome. J Neurosurg Spine. 2009;10(4):278-286.

15. Kokubun S, Ozawa H, Aizawa T, Ly NM, Tanaka Y. Spine-shortening osteotomy for patients with tethered cord syndrome caused by lipomyelomeningocele. J Neurosurg Spine. 2011;15(1):21-27.

16. Agarwalla PK, Dunn IF, Scott RM, Smith ER. Tethered cord syndrome. Neurosurg Clin N Am. 2007;18(3):531-547.

17. Lagae L, Verpoorten C, Casaer P, Vereecken R, Fabry G, Plets C. Conservative versus neurosurgical treatment of tethered cord patients. Zeitschrift für Kinderchirurgie. 1990;45(suppl 1):16-17.

18. Maher CO, Goumnerova L, Madsen JR, Proctor M, Scott RM. Outcome following multiple repeated spinal cord untethering operations. J Neurosurg. 2007;106(6 suppl):434-438.

19. Grande AW, Maher PC, Morgan CJ, et al. Vertebral column subtraction osteotomy for recurrent tethered cord syndrome in adults: a cadaveric study. J Neurosurg Spine. 2006;4(6):478-484. 
20. Safain MG, Burke SM, Riesenburger RI, Zerris V, Hwang SW. The effect of spinal osteotomies on spinal cord tension and dural buckling: a cadaveric study. J Neurosurg Spine. 2015;23(1):120-127.

21. Lin W, Xu H, Duan G, et al. Spine-shortening osteotomy for patients with tethered cord syndrome: a systematic review and meta-analysis. Neurol Res. 2018;40(5):340-363.

22. Safaee MM, Winkler EA, Chou D. Mini-open spinal column shortening for the treatment of adult tethered cord syndrome. J Clin Neurosci. 2017;44:315-319.

23. Zhang C, Chang C-C, Mummaneni PV, et al. Spinal column shortening versus revision detethering for recurrent adult tethered cord syndrome: a preliminary comparison of perioperative and clinical outcomes. J Neurosurg Spine. 2020;32(6):1-7.

\section{Disclosures}

Dr. Agarwal reported royalties from Thieme Medical Publishers and Springer International Publishing outside the submitted work. Dr. Mummaneni reported personal fees from Depuy Synthes, Stryker,
Globus, Springer International Publishing, and Thieme Publishers outside the submitted work and grants from Neurosurgery Research \& Education Foundation (NREF), AO Spine, International Spine Study Group (ISSG), and the National Institutes of Health. Dr. Chou reported personal fees from Globus and Orthofix outside the submitted work.

\section{Author Contributions}

Conception and design: Zhao, Shabani, Chou. Acquisition of data: Agarwal, Chou. Analysis and interpretation of data: Shabani, Agarwal, Chou. Drafting the article: Zhao, Shabani. Critically revising the article: all authors. Reviewed submitted version of manuscript: all authors. Approved the final version of the manuscript on behalf of all authors: Zhao. Administrative/technical/ material support: Shabani. Study supervision: Chou.

\section{Correspondence}

Zirun Zhao: Renaissance School of Medicine, Stony Brook University, Stony Brook, NY. zirun.zhao@stonybrookmedicine.edu. 